\title{
Arbuscular Mycorrhizal Fungal Assemblages Significantly Shifted upon Bacterial Inoculation in Non-Contaminated and Petroleum-Contaminated Environments
}

\author{
Dimitri J. Dagher ${ }^{1,+}$, Ivan E. de la Providencia ${ }^{2,+}$, Frédéric E. Pitre ${ }^{1}$, Marc St-Arnaud ${ }^{1}$ and \\ Mohamed Hijri 1,3,*(D) \\ 1 Institut de Recherche en Biologie Végétale, Université de Montréal and Jardin botanique de Montréal, \\ 4101 Sherbrooke est, Montréal, QC H1X 2B2, Canada; dimitri.dagher@umontreal.ca (D.J.D.); \\ frederic.pitre@umontreal.ca (F.E.P.); marc.st-arnaud@umontreal.ca (M.S.-A.) \\ 2 Neomed-labs 525 Boulevard Cartier O, Laval, QC H7V 4A2, Canada; iprovidencia@yahoo.com \\ 3 AgroBioSciences, University Mohammed VI Polytechnic, Lot 660-Hay Moulay Rachid, \\ Ben Guerir 43150, Morocco \\ * Correspondence: mohamed.hijri@umontreal.ca \\ + These authors contributed equally to this work.
}

Received: 21 March 2020; Accepted: 17 April 2020; Published: 21 April 2020

\begin{abstract}
Arbuscular mycorrhizal fungi (AMF) have been shown to reduce plant stress and improve their health and growth, making them important components of the plant-root associated microbiome, especially in stressful conditions such as petroleum hydrocarbons (PHs) contaminated environments. Purposely manipulating the root-associated AMF assemblages in order to improve plant health and modulate their interaction with the rhizosphere microbes could lead to increased agricultural crop yields and phytoremediation performance by the host plant and its root-associated microbiota. In this study, we tested whether repeated inoculations with a Proteobacteria consortium influenced plant productivity and the AMF assemblages associated with the root and rhizosphere of four plant species growing either in non-contaminated natural soil or in sediments contaminated with petroleum hydrocarbons. A mesocosm experiment was performed in a randomized complete block design in four blocks with two factors: (1) substrate contamination (contaminated or not contaminated), and (2) inoculation (or not) with a bacterial consortium composed of ten isolates of Proteobacteria. Plants were grown in a greenhouse over four months, after which the effect of treatments on plant biomass and petroleum hydrocarbon concentrations in the substrate were determined. MiSeq amplicon sequencing, targeting the $18 \mathrm{~S}$ rRNA gene, was used to assess AMF community structures in the roots and rhizosphere of plants growing in both contaminated and non-contaminated substrates. We also investigated the contribution of plant identity and biotope (plant roots and rhizospheric soil) in shaping the associated AMF assemblages. Our results showed that while inoculation caused a significant shift in AMF communities, the substrate contamination had a much stronger influence on their structure, followed by the biotope and plant identity to a lesser extent. Moreover, inoculation significantly increased plant biomass production and was associated with a decreased petroleum hydrocarbons dissipation in the contaminated soil. The outcome of this study provides knowledge on the factors influencing the diversity and community structure of AMF associated with indigenous plants following repeated inoculation of a bacterial consortium. It highlights the dominance of soil chemical properties, such as petroleum hydrocarbon presence, over biotic factors and inputs, such as plant species and microbial inoculations, in determining the plant-associated arbuscular mycorrhizal fungi communities.
\end{abstract}


Keywords: Arbuscular mycorrhizal fungi; plant-microbes interactions; microbial ecology; rhizosphere microbiome; bacterial inoculation; petroleum hydrocarbon contamination; amplicon sequencing; biodiversity; ribosomal RNA

\section{Introduction}

Plant-root associated microbes have been identified as major contributors to plant survival and health [1], as they can increase growth through a myriad of functions like the secretion of compounds such as phytohormones, organic acids, and antibiotics, thus improving access to nutrition and resistance to pathogens [2-5]. Moreover, in polluted environments, microorganisms can alleviate soil toxicity by reducing contaminant levels and/or bioavailability [6,7]. Considering the benefits and services microbes provide, their proper management is seen as a way to improve plant health, agricultural yields, as well as the rate of microbe mediated bioremediation. The application of microbial inoculants to the soil in order to modify certain processes and functions is a practice that has grown in popularity over the past few years [8,9]. While results obtained through function screening and cultivation in laboratory conditions are promising, the large-scale application in the field presents challenges in the establishment, persistence, and performance of microbes [10]. Influencing the composition and structure of the rhizosphere-associated microbial community by inoculating indigenous or allochthonous microorganisms is a promising research avenue. It has the potential to be applied at large scale because it does not necessarily rely on the persistence of the inoculants, so long as they induce lasting and desirable changes in microbiome. This could be accomplished through a modification in the soil environment, for example a $\mathrm{pH}$ change or nitrogen fixation [11,12], or possibly from an interaction with the native rhizosphere microbes. This would lead to significant changes in the microbial community and plant growth $[13,14]$.

Arbuscular mycorrhizal fungi (AMF) are major actors in the rhizosphere. They are ubiquitous soil microorganisms that develop obligatory associations with the roots of most terrestrial plant species and play an important role in their biological functioning [15]. They provide many benefits to their host plants, notably expanding the plant root system through their extensive mycelial network, which improves plant access to water and mineral nutrition [16-18]. Additionally, they can buffer abiotic stresses (i.e., salinity, drought, and trace metal toxicity) [19-21] and reduce the damages of root pathogens [22-24]. Beyond their interaction with their hosts, AMF mycelia also contribute to soil stability and structure [25] through the secretion of glomalin [26], a long-lasting glycoprotein known for increasing soil aggregation and water retention [27]. Previous experiments showed that plant rhizosphere inoculation with AMF improved the reduction of petroleum contaminants in comparison to non-inoculated plants $[28,29]$. As there is no information about the ability of AMF to degrade organic pollutants due to their lack of the required enzymes to break them down, the improved degradation of hydrocarbons is likely due to an AMF-mediated increase in plant roots exudation and/or stimulation of other microbial taxa. These taxa can then carry on the degradation of organic pollutants [30-32]. Some studies have shown the specific attachment to AMF hyphae of certain types of bacteria isolated from AMF spores and agricultural soils $[33,34]$, and the potential of these microbes to contribute to AMF P uptake [35]. Very few AMF taxa are commercially available for large-scale use [36]. Moreover, the success of AMF inoculation in polluted sites relies on many parameters including the soil and pollutant characteristics and the ability of the inoculated strains to compete with indigenous taxa. Therefore, in an effort to better understand how to influence plant-associated AMF communities, we investigated the contribution of plant species identity and repeated bacterial inoculation in shaping AMF assemblages in contaminated and uncontaminated substrates. We selected plants which were spontaneously growing in highly PH-contaminated sediments, as this would increase their chances of survival. We measured plant growth and $\mathrm{PH}$ dissipation at the end of the experiment. This inoculation-based approach 
could lead to a better understanding of the recruitment and management of the most widespread plant-fungus symbioses on earth in the service of phytotechnology.

\section{Materials and Methods}

Sediments contaminated with petroleum hydrocarbons were collected in October 2013 from a by-product sedimentation basin of a petrochemical plant located at Varennes, on the south shore of the St. Lawrence River near Montreal, Quebec, Canada ( $\left.45^{\circ} 41^{\prime} 56^{\prime \prime} \mathrm{N}, 73^{\circ} 25^{\prime} 43^{\prime \prime} \mathrm{W}\right)$. This basin was artificially made to collect wastewater of the petrochemical plant. It was used for several decades. The petrochemical plant stopped its industrial activities in 2008, and the site was colonized by spontaneous vegetation. No information on the vegetation nor arbuscular mycorrhizal fungal diversity were available for the site before its exploitation. Basic chemical characteristics of the sediments have been previously described $[14,37]$. Contaminated sediments were collected from the $0-10 \mathrm{~cm}$ layer of the decantation basin and brought back to the laboratory where they were thoroughly homogenized and transferred into $60 \times 29 \times 12 \mathrm{~cm}$ trays to a final volume of $18 \mathrm{~L}$ per tray and used as the growth substrate for plants. Non-contaminated field soil was also collected from a land plot adjacent to the contaminated basins and transferred to similar trays. Chemical characteristics of both substrates are available in Table S1. Initial hydrocarbons concentrations were $3055 \pm 188 \mathrm{mg} / \mathrm{kg}$ for C10-C50 and $35.4 \pm 2.6 \mathrm{mg} / \mathrm{kg}$ for polycyclic aromatic hydrocarbons (PAHs) in the contaminated treatments. Soils with these levels are considered to be significantly contaminated for agricultural, residential, and commercial use according to the Canadian soil quality guidelines.

\subsection{Seeds Collection and Germination}

We collected seeds from eight species of annual plants that spontaneously grew within the same contaminated basin in October 2013. Out of these eight species, we chose the following four plant species: Persicaria lapathifolia (L.) Delarbre, Lythrum salicaria L., Lycopus europaeus L., and Panicum capillare L., based on the availability of a sufficient number of seed pods on the day of collection, as well as on their germination success. The seeds were stratified in damp sand at $4{ }^{\circ} \mathrm{C}$ during 8 weeks, after which they were germinated in a 1:1 $(v / v)$ sand/calcined montmorillonite clay (Turface, Buffalo Grove, IL, USA) mix incubated at room temperature. Germinated seeds were planted in $50 \mathrm{~mL}$ multi-cell compartments filled with double autoclaved at $121^{\circ} \mathrm{C}$ all-purpose commercial potting soil mix (Scotts Premium potting soil, Rocky View County, AB, Canada). After three weeks of growth, seedlings were carefully transferred to the trays.

\subsection{Media Preparation and Isolation of Bacteria from the Contaminated Sediments}

One kilogram of contaminated sediments was mixed with one liter of sterile demineralized water and stirred for $24 \mathrm{~h}$ at room temperature. Subsequently, the supernatant was filtered through a 40 $\mu \mathrm{m}$ sieve and used to prepare a culture medium containing solely $8 \mathrm{~g} / \mathrm{L}$ of agarose. After being autoclaved for $30 \mathrm{~min}$ at $121{ }^{\circ} \mathrm{C}$ and left to cool for $45 \mathrm{~min}$, the medium was supplemented with $100 \mathrm{mg} / \mathrm{L}$ cycloheximide to inhibit any fungal growth. An inoculum was made up by serially diluting down to $10^{-7}$ a thoroughly vortexed stock suspension composed of $1 \mathrm{~g}$ of the same contaminated sediment in $9 \mathrm{~mL}$ of sterile demineralized water. From these serial dilutions, aliquots of $100 \mu \mathrm{L}$ from dilutions of $10^{-6}$ and $10^{-7}$ were spread on the culture plates, incubated at $27^{\circ} \mathrm{C}$ for one week, and checked daily for bacterial growth. Each colony was subcultured on the same medium in order to obtain a pure culture. The bacterial isolates were then stored at $4{ }^{\circ} \mathrm{C}$. The same procedure was repeated using an impoverished tryptic soy agar medium $(3 \mathrm{~g} / \mathrm{L})$ to isolate more copiotrophic bacteria.

\section{3. $16 S$ rDNA Amplification, Sequencing, and Identification of Bacteria}

Bacterial isolates were individually picked with $1 \mu \mathrm{L}$ sterile inoculation loops and directly added to a PCR master mix. 16S rRNA sequences were amplified using '27f' 5 ' AGAGTTTGATCMTGGCTCAG $3^{\prime}$ and '1492r' 5' TACGGYTACCTTGTTACGACTT 3' primers. The PCR master mix was made up of 
$1 \times$ PCR buffer, $0.5 \mathrm{mg}$ BSA, $2 \mathrm{mM} \mathrm{MgCL}_{2}, 0.2 \mu \mathrm{M}$ of each primer, $0.2 \mathrm{mM}$ of each deoxynucleotide triphosphate, one unit of Taq DNA Polymerase (Qiagen, Toronto, ON, Canada), and $1 \mu \mathrm{L}$ of bacterial cells as DNA template. Thermal cycling conditions were as follows: initial denaturation at $94^{\circ} \mathrm{C}$ for 3 min; 30 cycles at $95^{\circ} \mathrm{C}$ for $30 \mathrm{~s}, 55^{\circ} \mathrm{C}$ for $30 \mathrm{~s}$, and $72{ }^{\circ} \mathrm{C}$ for $1 \mathrm{~min}$; and a final elongation step at $72^{\circ} \mathrm{C}$ for $10 \mathrm{~min}$. PCR reactions were performed using an Eppendorf Mastercycler ProS (Eppendorf, Mississauga, ON, Canada). Sanger DNA sequencing was achieved using a commercial service provided at the Genome Quebec Innovation Centre (Montreal, QC, Canada). Briefly, a polymerase chain reaction (PCR) was first conducted using Big Dye 3.1 terminators and thermocyclers. The sequence was then determined by capillary electrophoresis, then analyzed using the ABI 3730xl Data Analyzer (Thermo Fisher Scientific, Mississauga, ON, Canada). Obtained sequences were identified using the NCBI nucleotide BLAST database. Identity was assigned based on the closest match with the highest coverage of our query sequences.

\subsection{Selection of Isolates and Production of a Bacterial Consortium}

A bacterial consortium that was used for the inoculation of plants was formed from a selection of bacterial isolates obtained from the contaminated sediments, as described above. To prepare this consortium, ten bacterial isolates belonging to the phylum Proteobacteria were selected (Table S2). Protobacteria were chosen because they have been identified as a dominant bacterial group within the same contaminated sediments in previous studies $[38,39]$. Selected bacterial isolates were individually subcultured in impoverished Tryptic Soy Broth (TSB, $3 \mathrm{~g} / \mathrm{L}$ ) at $27^{\circ} \mathrm{C}$ for $72 \mathrm{~h}$, after which the liquid cultures were centrifuged at $5000 \mathrm{rpm}$ for $10 \mathrm{~min}$ at $4{ }^{\circ} \mathrm{C}$. The supernatant was then discarded, and the resulting bacterial cell pellet was re-suspended in $1 \mathrm{~L}$ of a sterile isotonic $0.154 \mathrm{M} \mathrm{NaCl}$ solution. Cell counts for each isolate were then performed using a Neubauer improved hemocytometer (Sigma-Aldrich, Oakville, ON, Canada), and the inoculum was made up by suspending all the selected isolates in equal numbers in a final volume of $2.4 \mathrm{~L}$ at a final concentration of $2.4 \times 10^{9} \mathrm{CFU} / \mathrm{mL}$.

\subsection{Mesocosm Experiment Design and Inoculation}

A randomized complete block design with two factors-substrate contamination and inoculation-with four replicates each was setup in four blocks (one replicate per block). The treatments were the following: non-contaminated field soil not inoculated (NB-), non-contaminated field soil inoculated with the bacterial consortium $(\mathrm{NB}+)$, contaminated sediments not inoculated (CB-), and contaminated sediments inoculated with the bacterial consortium (CB+). Each tray was planted with the plant species listed above in three rows, separated by $7.5 \mathrm{~cm}$. Within each row, the four plant species were randomly distributed in four planting points, each composed of a cluster of four individual seedlings from the same plant species. These points were spaced at $12.5 \mathrm{~cm}$ intervals. Plants were watered several times weekly, as needed throughout the experiment. No fertilization was applied. Bacterial inoculation was performed twice, two and four weeks after planting the trays. At both applications, each tray received $300 \mathrm{~mL}$ of the bacterial consortium, which gave a concentration of $4 \times 10^{7} \mathrm{CFU} / \mathrm{g}$ of dry soil. The planting design in each tray as well as pictures of the experimental setup are available in the Supplementary Material file, Figure S1.

\subsection{Data Collection and Harvest}

The plants were harvested after 16 weeks of growth. At harvest, each plant cluster was carefully removed from the substrate to avoid root damage, and aerial parts were separated from the roots. The substrate was gently shaken off from the roots, and the portion still attached (considered as the rhizospheric soil) was collected and used for DNA extraction. Subsequently, the root system was thoroughly washed with tap water to eliminate the remaining substrate particles. In total, there were 12 rhizospheric soil samples and 12 root samples from each tray (one sample per plant cluster, i.e., three samples for each plant species), hence 384 samples were taken for the whole experiment. All samples were stored at $-80{ }^{\circ} \mathrm{C}$ until processing. Aerial plant parts were dried in the oven for 
$72 \mathrm{~h}$ at $60^{\circ} \mathrm{C}$ and weighted. A plant sampling example can be found in Supplementary Figure S2. In addition, soil composite samples (3 subsamples) from each of the contaminated mesocosms were collected for petroleum hydrocarbon analysis. C10-C50 aliphatic hydrocarbons and polycyclic aromatic hydrocarbons levels analysis was performed using a commercial service (AGAT labs, Montreal, QC, Canada).

\subsection{DNA Extraction, PCR Amplification and Illumina MiSeq Sequencing}

Total genomic DNA was extracted from plant roots and rhizospheric soil samples using the Nucleospin ${ }^{\circledR}$ Soil Kit (Macherey Nagel, Bethlehem, PA, USA) following the manufacturer's instructions. The isolated DNA was then diluted tenfold in Milli-Q type 1 sterile water to reduce the risk of PCR inhibition by PH contaminants and humic substances. A two-step nested PCR was performed in order to amplify part of the $18 \mathrm{~S}$ rRNA gene of arbuscular mycorrhizal fungi using primers AML1 (5'-ATCAACTTTCGATGGTAGGATAGA-3') and AML2 (5'-GAACCCAAAC ACTTTGGTTTCC-3') according to Lee et al. [40] for the first step, followed by an in-house set of internal primers: nu-SSU-0595-5' CGGTAATTCCAGCTCCAATAG / nu-SSU-0948-3' TTGATTAATGA AAACATCCTTGGC with overhang adapter sequences to produce a final amplicon size of $\sim 400 \mathrm{bp}$ [41]. Finally, Illumina Miseq-specific indexes were attached to the generated amplicons using the Nextera XT V2 kit using a limited-cycles PCR as recommended by the manufacturer. The indexed sequences were then purified and normalized using the SequalPrep ${ }^{\mathrm{TM}}$ Normalization Plate Kit (Thermo Fisher Scientific, St-Laurent, QC, Canada), after which they were pooled at equimolar concentration and sequenced on an Illumina MiSeq sequencer. The 384 samples were multiplexed in one flow cell for sequencing using the 600 cycle MiSeq Reagent Kit v.3 in 2×300 bp configuration (Illumina Inc., San Diego, CA, USA).

\subsection{Evaluation of the AMF Colonization of Plants Roots}

Composite root samples from each plant cluster were surface rinsed in tap water to remove any remaining soil debris and cut in fragments $1 \mathrm{~cm}$ long. They were then cleared in a $10 \% \mathrm{KOH}$ solution, acidified using acetic acid, and stained with trypan blue, following a microwave-assisted protocol [42]. Root fragments were mounted onto microscope slides in lactoglycerol medium (300 mL lactic acid, 300 $\mathrm{mL}$ glycerol, $400 \mathrm{~mL}$ double-distilled water), and colonization percentages were evaluated using the magnified intersections method [43], with 150 intersects examined per plant cluster for the presence of mycorrhizal structures.

\subsection{Sequence Processing and Details of the Pipeline}

Read assembly and primer trimming were done in Mothur (v.1.34.4). The rest of the processing was performed in QIIME (v.1.9), following the Brazilian Microbiome Project 18S profiling pipeline [44,45]. In Mothur, the reads from each sample were assembled using the 'make.contigs' command. This generated a .fasta file containing the assembled reads. Primers were then removed with 'trim.seqs', after which the sequences were exported to QIIME. Special labels were then added for compatibility, with the 'add.qiime.labels.py' command. Using the Usearch7 sequence analysis tool via QIIME implementation, the dataset was reduced to unique sequences using '-derep_fulllength', which we sorted by decreasing cluster size and removed singletons with '-sortbysize'. The sequences were then clustered by operational taxonomic unit (OTU) using a 97\% identity threshold using the UPARSE method, and further sequencing errors were removed with '- uchime_denovo'. Representative sequences of the OTUs were aligned with '-align.seqs' using the Silva eukaryote database (release 132), and filtered ('-filter.alignment' -e 0.10 and -g 0.80). We then produced an OTU table at $97 \%$ similarity, and sequences that did not classify as Glomeromycota were removed with 'filter_taxa_from_otu_table.py'. Finally, we subsampled the sequences, so each sample had the same number of sequences (150). Raw sequence data have been deposited in NCBI's Sequence Read Archive and can be found under BioProject number PRJNA591301. An operational taxonomic unit (OTU) table of the dataset used for the analyses can be found in Table S3. 


\subsection{Statistical Analyses}

The effect of inoculation with the bacterial consortium on plant biomass and concentration of C10-C50 petroleum hydrocarbons and polycyclic aromatic hydrocarbons (PAH) at the end of the experiment were analyzed using ANOVA in JMP ${ }^{\circledR}$ 11.0.0 statistical software (SAS Institute Inc.). The effect of inoculation and plant species identity on the alpha diversity indices of AMF communities (Chao1, Shannon, and Pielou's equitability) was also analyzed with ANOVA. The effects of the inoculation with the bacterial consortium and plant species identity on AMF community structure in the rhizosphere were analyzed using R (v3.2.0, The R Foundation for Statistical computing). Principal coordinate analysis (PCoA) based on Bray-Curtis dissimilarity matrixes was used to reveal the effect of treatments and biotope (plant roots and rhizospheric soil) on AMF communities' structures, while Permanova was used to test the effect of treatments on the beta diversity of AMF communities in the substrate.

\subsection{Phylogenetic Analysis}

Sequences of the operational taxonomic units (OTUs) obtained from the bioinformatic pipeline were combined with all the AMF sequences from Kruger et al. [46], along with the closest matches from the MaarjAM database [47], and aligned using the MUSCLE v.3.8 [48] plugin in Geneious v.6 [49]. We determined the DNA substitution model in jModelTest2 v.2.1.9 [50,51] using the Bayesian information criterion calculations. A phylogenetic analysis was then performed using the Mr.Bayes v.3.2.6 [52] plugin in Geneious v.8 (Biomatters, Auckland, New Zealand). We adjusted the temperature parameter for heating chains in order to keep the swap acceptance rate between $10 \%$ and $70 \%$. The number of trees saved was 6000, and the first 1000 trees were ignored before the computation of the consensus tree with the Bayesian posterior probabilities. The tree was rooted using outgroup sequences.

\section{Results}

\subsection{Sequence Processing}

Sequencing of $18 \mathrm{~S}$ rRNA gene amplicons generated a total of $13,087,745$ reads, of which 5,873,061 usable AMF sequences with an average length of $408 \mathrm{bp}$ were retained after processing and quality filtering. All non-glomeromycotan sequences were excluded from the dataset. Reads number per sample ranged from 20 to 42,410 . The dataset was subsampled to 150 sequences per sample for all analyses, in order to account for the disparity in reads numbers while minimizing the loss of samples. Sixteen samples out of 384 did not meet this cutoff criterion and were ignored for the analyses. Only OTUs with a cumulative abundance greater than $0.5 \%$ for the whole dataset were considered, yielding 23 OTUs at a $97 \%$ similarity threshold. Good's coverage indices ranged between $96 \%$ and $100 \%$ for all samples, indicating that most of the diversity was captured.

\subsection{Diversity and Identity of AMF Taxa}

All alpha diversity results can be found in Table 1. AMF diversity was significantly influenced by inoculation, soil contamination, plant species identity, and biotope, as shown by the Shannon diversity indices of AMF taxa (Table S4). There were also significant inoculation*contamination, plant species*biotope, and biotope*contamination interactions. Overall, AMF communities in the non-contaminated soil had significantly higher Shannon diversity indices than those in the contaminated soil. Inoculation was also significantly associated with higher scores, but this effect was only observed in the non-contaminated soil. Moreover, significantly different diversity scores between plant species were only observed in the roots and not in the rhizosphere: P. lapathifolia-associated AMF communities in the roots had a significantly lower Shannon diversity score than those associated with the other plant species (Table S4). Chao1 species richness estimator was significantly influenced by substrate contamination, biotope, and plant species (Table S5). There was significant plant species*inoculation, plant species*biotope, and plant species*contamination interactions. Overall, Chao1 estimated species richness was significantly higher in the non-contaminated soil and in the roots in comparison to 
the contaminated sediments and rhizosphere respectively (Table S5). The estimated richness was differentially influenced by inoculation among plant species, biotope, and contamination as indicated by the significant interaction terms. There was no significant difference between plant species that received inoculation, whereas richness was significantly higher in L. salicaria than P. capillare and P. lapathifolia non-inoculated treatments. Additionally, estimated richness was similar between plant species in the non-contaminated soil, but significantly higher in L. salicaria than P. capillare and P. lapathifolia (Table S5). Pielou's equitability index reflects how evenly species (in this case OTU) are represented in each sample. It varies between 0 and 1, with 1 meaning that all OTUs in the samples are represented by the same number of sequences [53]. We found that AMF communities' evenness was significantly influenced by the substrate contamination, inoculation, and biotope (Table S6). Overall, inoculated AMF assemblages showed a significantly higher evenness than those from the non-inoculated communities. Additionally, there was significant plant species*biotope and biotope*contamination interactions. Evenness was not different among plant species in the rhizosphere, but there was significant difference in the roots, with L. europaeus showing higher scores than P. lapathifolia. Moreover, evenness was similar in the roots and rhizosphere of plants in the contaminated soil, but it was significantly higher in the roots of plants in the non-contaminated soil in comparison with the rhizosphere (Table S6). The 23 AMF OTUs belonged to 15 virtual taxa (VTX) based on the MaarjAM's database (Öpik et al., 2010). The taxonomic affiliation of each OTU was confirmed by the phylogenetic analysis (Supplementary Material, Figure S3). The OTUs belonged to Glomeraceae (16), Claroideoglomeraceae (4), Acaulosporaceae (1), Diversisporaceae (1), and Paraglomeraceae (1) families. Overall, OTUs belonging to Glomeraceae and Claroideoglomeraceae accounted for most of the sequences, irrespective of inoculation, plant species, biotope (roots, rhizosphere), and contamination. They represented more than $96 \%$ of the sequences in the contaminated soil and more than $73 \%$ in the non-contaminated. In the roots of plants growing in non-contaminated soil, sequences belonging to Glomus sp. were the most abundant irrespective of inoculation. Relative abundances ranged from 27.8\% (VTX00247) to 40.6\% (VTX00143) in the contaminated mesocosms (Figure 1A). On the other hand, rhizospheric samples were dominated by Paraglomus sp. VTX00281 with values ranging between $39.4 \%$ and $41.6 \%$ (Figure 1A). In the non-contaminated sediments (Figure 1B), root samples were dominated by an OTU identified as VTX00114, which belong to Rhizophagus irregularis and ranged from $55.8 \%$ to $63 \%$. The rhizosphere was dominated by Claroideoglomus VTX00193, representing 54.8\% to 57.6\% of the AMF community.

Table 1. Alpha diversity indices of AMF communities as calculated in the different treatments and biotopes.

\begin{tabular}{|c|c|c|c|c|c|c|c|c|c|}
\hline \multirow[b]{2}{*}{ Contamination } & \multirow[b]{2}{*}{ Inoculation } & \multirow[b]{2}{*}{ Biotope } & \multirow[b]{2}{*}{$\begin{array}{c}\text { Plant } \\
\text { Species }\end{array}$} & \multicolumn{2}{|c|}{ Shannon } & \multicolumn{2}{|c|}{ Chao 1} & \multicolumn{2}{|c|}{ Pielou's Equitability } \\
\hline & & & & Mean & Std Dev & Mean & Std Dev & Mean & Std Dev \\
\hline \multirow{16}{*}{ Contaminated } & \multirow{8}{*}{ Inoculated } & \multirow{4}{*}{ Rhizosphere } & LE & 1.7 & 0.38 & 9.96 & 3.35 & 0.56 & 0.12 \\
\hline & & & LS & 1.96 & 0.43 & 8.92 & 2.37 & 0.64 & 0.14 \\
\hline & & & PC & 1.94 & 0.43 & 10.88 & 4.43 & 0.62 & 0.13 \\
\hline & & & PL & 1.61 & 0.39 & 8.6 & 3.57 & 0.57 & 0.13 \\
\hline & & \multirow{4}{*}{ Roots } & LE & 2.39 & 0.22 & 10.87 & 1.38 & 0.71 & 0.07 \\
\hline & & & LS & 1.87 & 0.64 & 10.32 & 3.67 & 0.57 & 0.16 \\
\hline & & & PC & 2.08 & 0.27 & 8.58 & 1.43 & 0.69 & 0.07 \\
\hline & & & PL & 1.73 & 0.5 & 8.42 & 3.05 & 0.58 & 0.11 \\
\hline & \multirow{8}{*}{ Non-inoculated } & \multirow{4}{*}{ Rhizosphere } & LE & 1.86 & 0.36 & 9.3 & 2.82 & 0.62 & 0.11 \\
\hline & & & LS & 1.87 & 0.5 & 7.74 & 2.16 & 0.65 & 0.14 \\
\hline & & & PC & 1.74 & 0.65 & 8.86 & 4.5 & 0.61 & 0.14 \\
\hline & & & PL & 1.68 & 0.32 & 7.7 & 2.63 & 0.62 & 0.12 \\
\hline & & \multirow{4}{*}{ Roots } & LE & 2.09 & 0.27 & 9.25 & 1.78 & 0.67 & 0.07 \\
\hline & & & LS & 2.25 & 0.42 & 17.5 & 2.93 & 0.6 & 0.09 \\
\hline & & & PC & 1.75 & 0.62 & 8.58 & 2.85 & 0.59 & 0.15 \\
\hline & & & PL & 1.39 & 0.51 & 8.36 & 3.71 & 0.48 & 0.13 \\
\hline
\end{tabular}


Table 1. Cont.

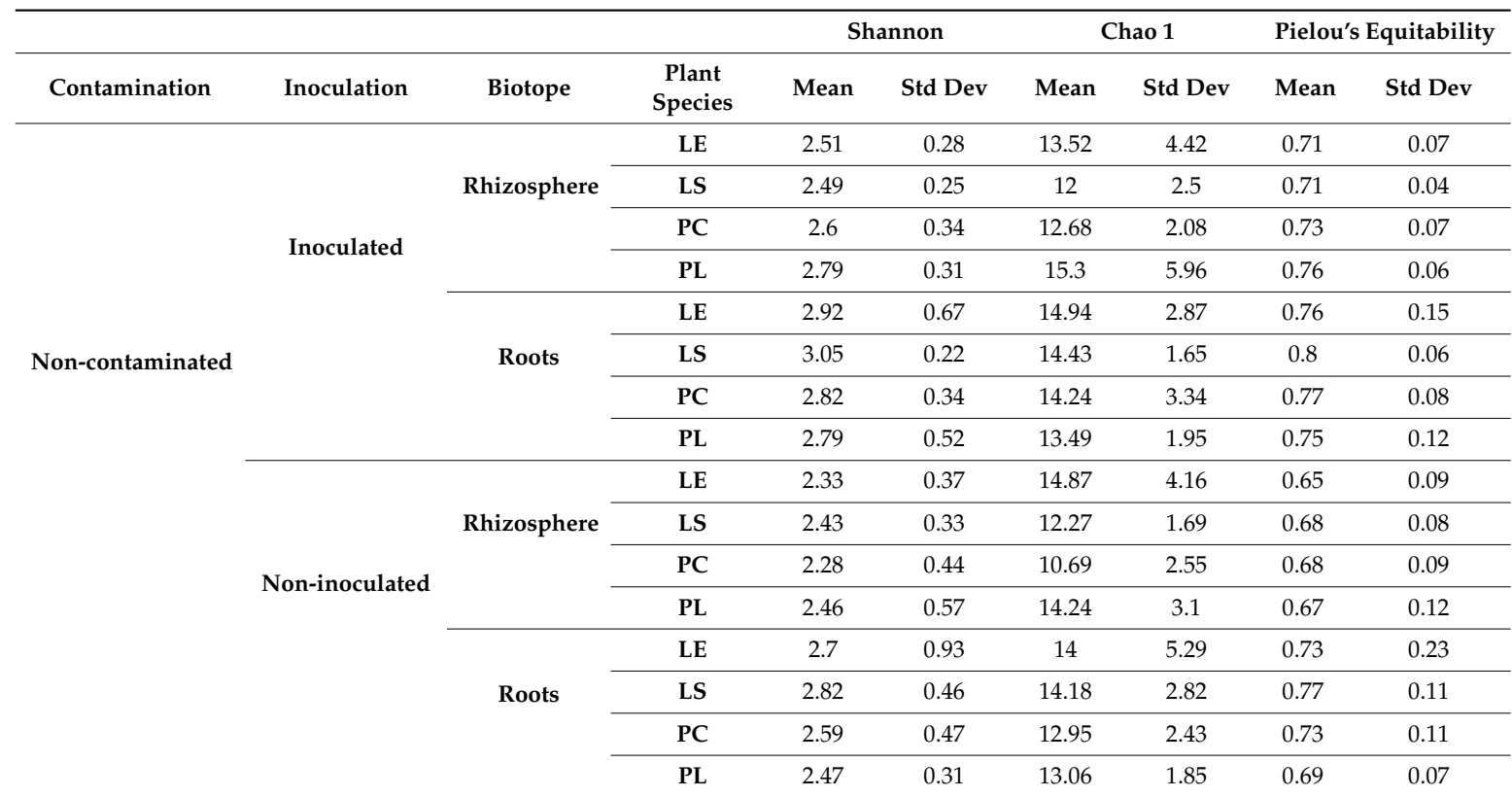

LE: Lycopus europaeus; LS: Lythrum salicaria; PL: Persicaria lapathifolia; PC: Panicum capillare. Std. Dev: Standard deviation.

\subsection{AMF Community Structure}

Substrate contamination influenced the AMF communities, as illustrated by the PCoA analysis of all samples showing that the samples from contaminated and non-contaminated soil mostly clustered closely together on opposite sides of the biplot (Figure 2A). Permanova analysis showed a significant effect of the substrate contamination level and biotope (Table S7). Noteworthy is the effect of contamination that explained $52.6 \%$ of the variation in the AMF communities $(p=0.001)$. There was also a significant contamination*biotope interaction. In each substrate contamination level, the plant biotope (roots vs. rhizosphere) significantly influenced the structure of AMF assemblages, as shown by the PCoA analysis, with a cleaner separation between communities in the non-contaminated soil (Figure 2B,C). Moreover, UPGMA (Unweighted pair group method with arithmetic mean) hierarchical clustering analysis on the average relative abundance of each of the AMF OTUs in the experimental blocks also showed the influence of biotope on AMF assemblages, as roots and rhizosphere samples belonged to different clusters (Figure 3A,B). The biotope explained 3\% of the variation in the AMF communities $(p=0.001)$ in the non-contaminated substrate, and $5.7 \%$ in the contaminated sediments $(p=0.001)$, as per the Permanova analysis (Table S7). In the non-contaminated substrate, AMF communities clustered together in the rhizosphere based on the inoculation, and to a lesser extent in the roots following UPGMA clustering analysis (Figure 3B). On the other hand, inoculation did not induce a clear clustering in the contaminated soil, especially in the roots (Figure 3A). PCoA analysis showed that the root and rhizosphere AMF communities from the non-contaminated substrate underwent a shift in structure following inoculation (Figure 2B), as confirmed by the Permanova with inoculation explaining $3.4 \%$ of the variation $(p=0.003)$ in the roots, while in the rhizosphere, inoculation influenced $7.2 \%$ of the community structure variation $(p=0.001)$. On the other hand, inoculation significantly influenced the AMF communities only in the roots from the contaminated substrate and accounted for $2 \%$ of the variation $(p=0.028)$ and did not have a significant influence in the rhizosphere (Figure 2C). Since the interaction between substrate contamination level and plant biotope was significant, we also assessed the influence of plant species identity on the AMF community structure within each substrate contamination level and biotope using Permanova. In the non-contaminated substrate, plant species identity accounted for $9.5 \%(p=0.001)$ of the variation in the roots and $6.7 \%$ in the rhizosphere $(p=$ 0.003). Similarly, in the contaminated substrate, plant identity significantly explained $9.7 \%(p \leq 0.001)$ 
of the variance in the roots and $5.7 \%(p=0.009)$ in the rhizosphere. More details on the Permanova results can be found in Table S7.

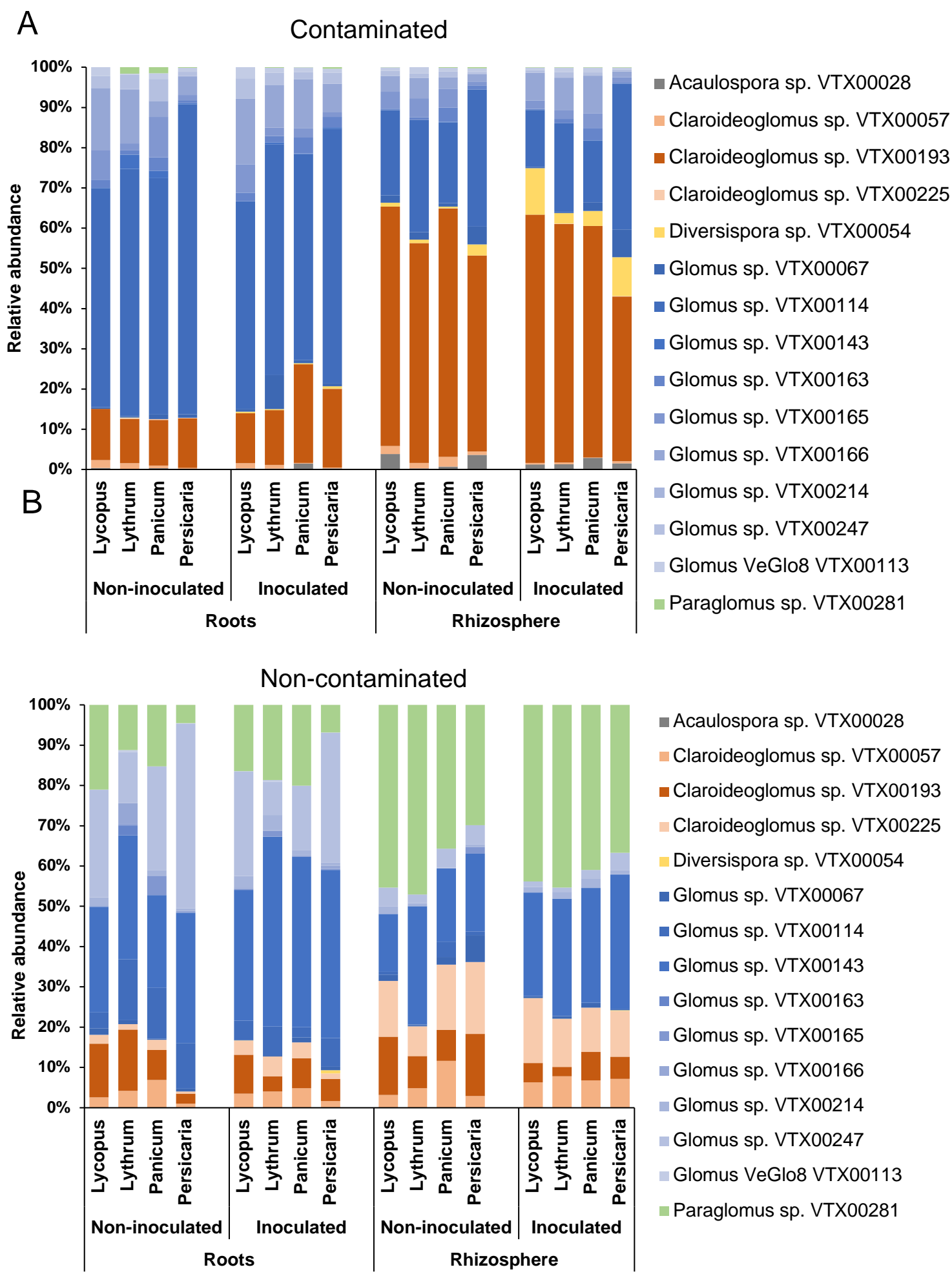

Figure 1. Relative abundance of AMF taxa detected in the roots and rhizospheres of plants from the contaminated substrate (A) and the non-contaminated substrate (B), inoculated or not-inoculated with the bacterial consortium. LE: Lycopus europaeus; LS: Lythrum salicaria; PC: Panicum capillare; PL: Persicaria lapathifolia. 

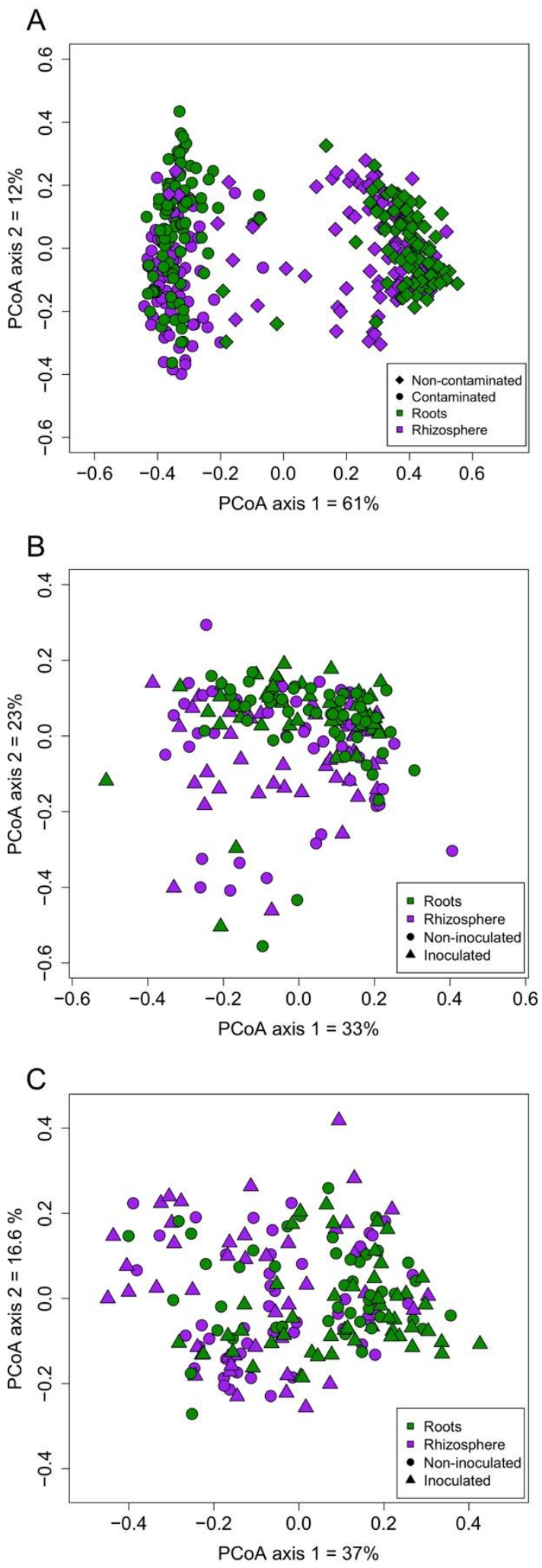

Figure 2. Principal coordinate analysis based on the Bray-Curtis dissimilarity of (A) roots and rhizosphere AMF communities together from both type of substrates (non-contaminated soil or contaminated sediments), and separately from (B) the non-contaminated soil and (C) the contaminated sediments. 
A
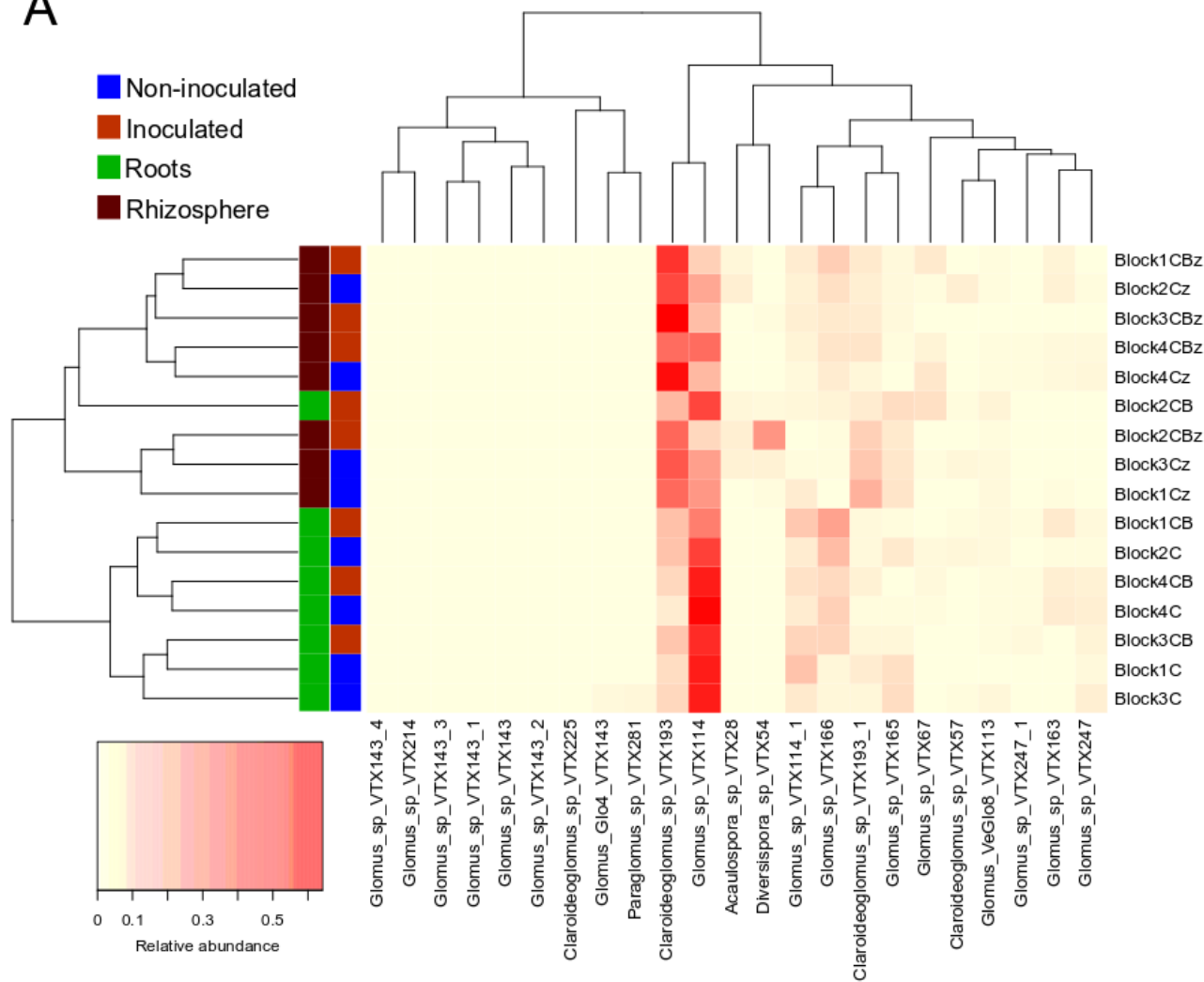

B

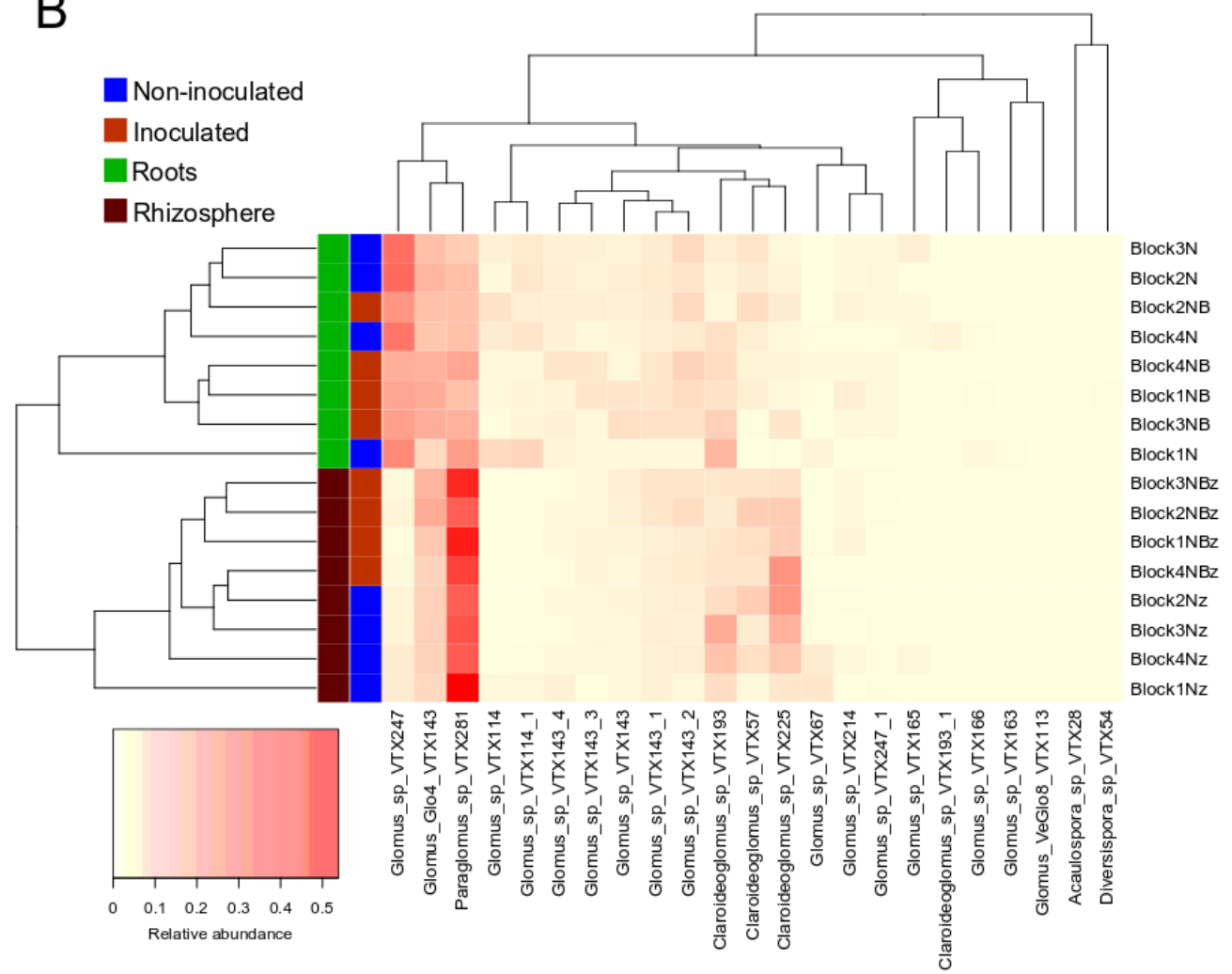

Figure 3. Heat map and UPGMA clustering based on the relative abundance of AMF OTUs in roots and rhizosphere in each block, from the different treatments in the contaminated soil (A) and the non-contaminated sediments (B). The colors of the last two squares on the left of rows represent the origin and treatment of each sample (biotope and inoculation). 


\subsection{Plant Dry Biomass}

Substrate contamination significantly affected plant biomass since plants growing in the contaminated substrate produced significantly less dry biomass than those growing in the non-contaminated substrate for all plant species $(p<0.0001)$. Plant species identity also showed a significant effect $(p<0001)$, as well as inoculation $(p=0.0043)$ (Figure $4 \mathrm{~A}, \mathrm{~B})$. There was a significant contamination * plant species effect $(p<0001)$, where biomass production was significantly different between plant species in the non-contaminated soil, but not in the contaminated setting (Table S8).
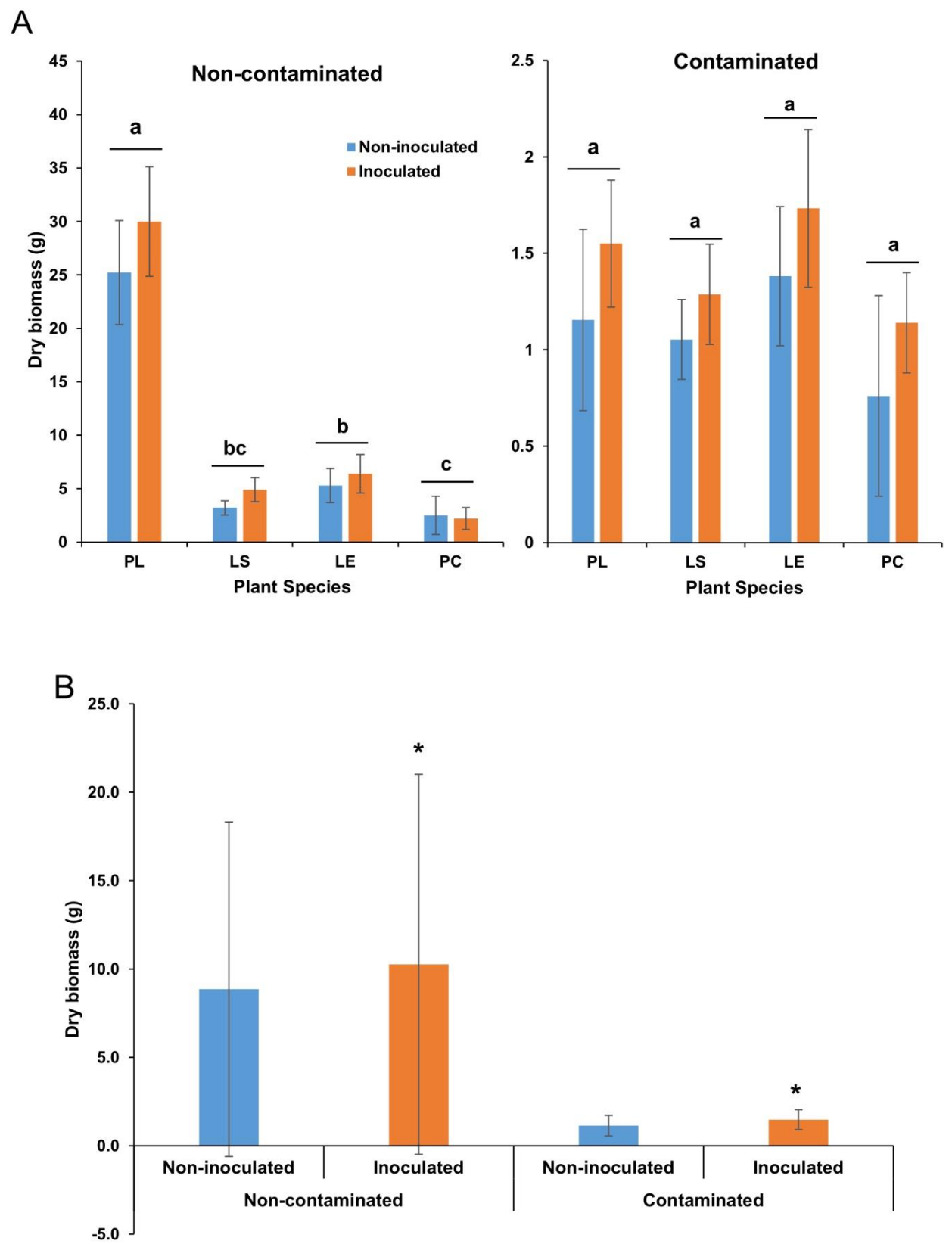

Figure 4. Effect of inoculation on average plant aerial dry biomass for each plant species (A) and overall (B), in the non-contaminated soil and the contaminated sediments. Errors bars are standard deviations. Within each contamination level, treatments not sharing the same letter are significantly different (A). Asterisks indicate a significant difference between the two treatments in each contamination level (B). PL: Persicaria lapathifolia; LS: Lythrum salicaria; LE: Lycopus europaeus; PC: Panicum capillare. N=12 for each species. 


\subsection{AMF Root Colonization}

The microscope examination of trypan blue-stained roots revealed the occurrence of AMF structures associated with the roots, such as hyphopodia, intraradical mycelium, arbuscules, and vesicles (Figure S4). Assessment of the percentage of root length colonized using the magnified intersect method showed that the colonization rate was significantly higher $(p<0.001)$ in the roots of plants that grew in the contaminated sediments than those in non-contaminated soil for all plant species (Table S9). Colonization ranged from $25 \%$ to $67 \%$ of root length in the contaminated sediments and from $12 \%$ to $23.5 \%$ in the non-contaminated soil (Figure $5 \mathrm{~A}$ ). Inoculation did not influence root colonization in the non-contaminated soil, but it significantly increased the root colonization in the contaminated sediments (Figure 5A).
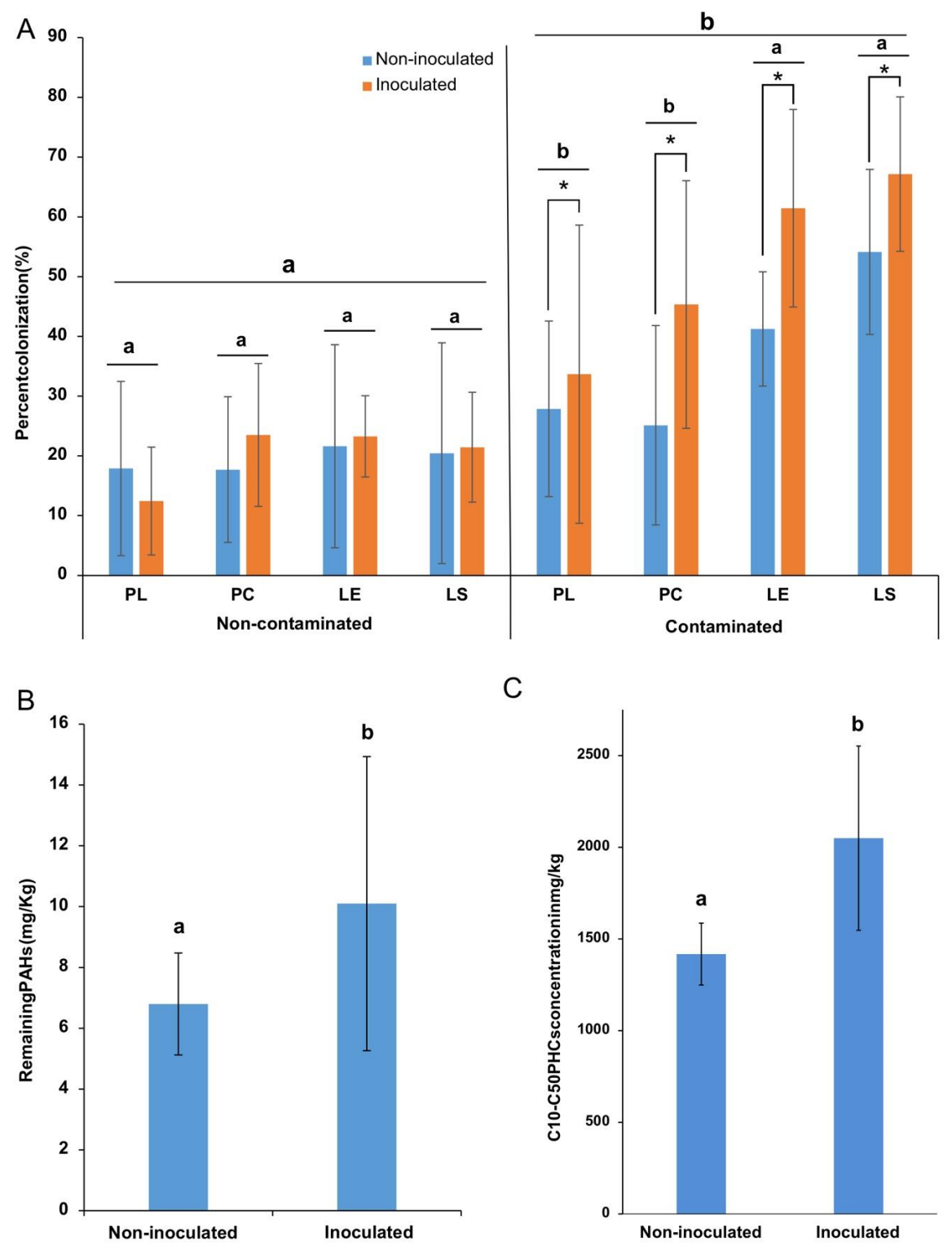

Figure 5. (A) Average AMF root colonization percentage for each plant species in both soil contamination levels. PL: Persicaria lapathifolia; LS: Lythrum salicaria; LE: Lycopus europaeus; PC: Panicum capillare. Within each contamination level, plant species not sharing the same letter are significantly different. For each plant species, an asterisk denotes a significant difference between inoculation treatments. (B) Average remaining PAHs and (C) C10/C50 PHs in the contaminated sediments at harvest. Errors bars are standard deviations. 


\subsection{Effect of Inoculation on PH Concentrations}

Bacterial inoculation also influenced the concentrations of PAHs (Figure 5B) and aliphatic hydrocarbons (C10-C50 fraction; Figure 5C) in the contaminated sediments at the end of the experiment. Intriguingly, there was significantly less PAHs $(p=0.0181)$ in the non-inoculated compared to the inoculated treatments (Figure 5B). Values ranged from $6 \pm 1.14 \mathrm{mg} / \mathrm{kg}$ in the non-inoculated to $10.7 \pm 1.11 \mathrm{mg} / \mathrm{kg}$ in the inoculated microcosms. The same trend was observed for aliphatic petroleum hydrocarbons (Figure 5C), with levels ranging from $1360 \pm 147 \mathrm{mg} / \mathrm{kg}$ in the non-inoculated to $2050 \pm 502 \mathrm{mg} / \mathrm{kg}$ in the inoculated microcosms.

\section{Discussion}

The present study shows that the physicochemical properties of the plant substrate that was contaminated or not with petroleum hydrocarbons strongly shaped the AMF communities associated with the plant roots and rhizosphere. Moreover, within a given substrate contamination level, plant identity, biotope, and inoculation with the bacterial consortium also had significant effects on the structure of AMF assemblages.

\subsection{Contamination and Biotope Shape AMF Communities}

In this experiment, AMF rhizospheric and root communities of plants growing in non-contaminated soil and PH-contaminated sediments were inoculated using a bacterial consortium formed of multiple Proteobacteria isolates. Overall, neither plant species identity nor bacterial inoculation were significant determinants of AMF root and rhizosphere assemblages, obviously because the effect of soil contamination and the differences between biotopes were so large that it overwhelmed the more subtle effects of the other factors, which still were enlightened by interactions such as inoculation*biotope in the non-contaminated soil, inoculation*plant species in the rhizosphere, and contamination*inoculation in both roots and rhizosphere. However, looking at each level of soil contamination, we found significant effect of biotope (rhizosphere vs. roots) and, to a lesser extent but also significant, plant species identity and bacterial inoculation effects. It is still unclear how to manipulate different environmental factors in order to influence the AMF communities to a predictable state, as multiple studies found different patterns. For example, Xu et al. [54] sampled Chenopodium ambrosioides plants from five different sites and found, using high-throughput sequencing, that soil properties were the major factor explaining the variation in AMF communities, followed by soil habitat (rhizosphere vs. roots), while plants showed little effect [54]. Contrarily, Krüger et al. [55] found that it was the plant communities that shaped the AMF assemblages, rather than soil properties, during primary succession on mine spoils [55]. In another study, the authors analyzed rhizospheric soil from different plants sampled from five sites in the Tibetan alpine steppe; they found that plant species identity did not significantly explain the variation in the AMF assemblages, but rather it was the precipitation which was associated with an increased hyphal length density [56]. Finally, Dumbrell et al. [57] sampled 28 plants species growing along a $\mathrm{pH}$ gradient and found that it was the $\mathrm{pH}$, rather than plants, that structured AMF communities [57]. While of different conclusions, the aforementioned studies showed that the soil environment is generally at the center of the process of shaping the AMF communities; therefore, an approach where the soil parameters would be precisely manipulated might be a successful method to shape microbial assemblages. Such shaping of microbial communities has been observed in the human gut microbiome, where significant, reproducible, and long-lasting changes were induced by osmotic stress caused by the laxative polyethylene glycol, which disrupts the mucus barrier and causes an IgG response from the immune system against the resident highly abundant bacteria and a modification of the cytokinin levels [58]. This showed that a modification of the environmental parameters triggered a cascade of reactions that led to lasting and predictable changes. In the present experiment, we tried to modify the community structure through a biotic disturbance in the form of a repeated inoculation of a bacterial consortium. We 
hypothesized that this inoculation could change the soil environment (at least temporarily) through the bacterial metabolites produced by the members of the consortium and their interaction with resident microorganism, as well as the decomposition of dead bacterial cells. As a result, the AMF community structure would be altered since AMF have been shown to interact with their surrounding microorganisms [59-62]. In fact, the bacterial inoculation did cause significant shifts in the AMF community structure in both biotopes (roots vs. rhizosphere) growing in non-contaminated field soil, but in the contaminated sediments only the AMF community of roots exhibited significant shifts. The toxicity caused by the high concentrations of PH might likely make the growing environment more selective for stress-tolerant strains of AMF, thus overriding the influence of the biotic disturbance. On the other hand, while insignificant in the rhizosphere, inoculation caused significant shifts in the AMF in roots, suggesting a possible plant-mediated restructuring of the assemblages. This further complicates the task of producing a reproducible and predictable method for shaping community structure, as it was shown that plant species identity counts in the selection of microbial associates.

\subsection{Glomeraceae and Claroideoglomeraceae Dominate Most Samples}

OTUs belonging to the Glomeraceae dominated the roots of all plant species in both contaminated and non-contaminated substrates, and with or without inoculation. OTUs related to Glomus sp. were the most abundant in the roots of plants in non-contaminated substrate, while in the contaminated substrate roots were dominated by Rhizophagus sp. VTX114 in. On the other hand, an OTU identified as Paraglomus sp. dominated the rhizosphere soil of plants in non-contaminated soil, while Claroideoglomus sp. was the most abundant in the rhizospheric soil in contaminated sediments. Previous field studies in the same geographical area from which the substrates used in this experiment were sourced have reported higher abundances of Paraglomus in non-contaminated soil and Claroideoglomus in contaminated sediments, as well as a dominance of OTUs related to Rhizophagus sp. in plant roots in comparison to rhizospheric soil $[60,63,64]$. We found that the structure of AMF in the roots of plants was different at each level of contamination; however, the communities were dominated by Glomeraceae strains in both cases, while the rhizosphere was dominated by non-Glomeraceae OTUs. AMF colonize roots using different strategies; for example, some species produce a larger mycelial network in the rhizosphere before penetrating the roots (e.g., Gigaspora spp.), while others readily colonize the roots without producing an extensive network of mycelium outside the roots (e.g., Glomus spp.) [65]. This could be explained by the fact that root colonization strategies of AMF species vary with their taxonomic affiliation, and that members of the Glomeraceae family more readily colonize the roots than produce extraradical structures [66]. Such species would be ideal candidates for inoculating plants in contaminated environments to assure adequate plant colonization.

\subsection{Contamination Increases Root AM Colonization}

We found that AMF root colonization percentages in the four plant species collected from the contaminated sediments were significantly higher than their counterpart grown in non-contaminated soil. De la Providencia, Stefani, Labridy, St-Arnaud, and Hijri [63] sampled during two successive years $P$. capillare plants from the same location from which the contaminated sediments for the present experiment originated. They found that in P. capillare, colonization percentages were $4.84 \%$ in 2011 and $12 \%$ in 2012 [63], which were lower than the levels found in the same plant species in this experiment. Plants are subjected to the natural elements and different edaphic factors in situ, which might explain the observed difference. It should also be noted that contamination levels found at the site were much higher than those recorded in this greenhouse experiment, reaching up to $41,000 \mathrm{mg} / \mathrm{kg}$ of C10-C50 hydrocarbons. This difference likely was due to the natural weathering process, microbial activity, and volatilization. Higher levels of PHs might stimulate a stronger mycorrhizal colonization of the roots as observed here; nonetheless, extreme levels are likely to inhibit it. Cabello [67] found that the AMF root colonization in plants sampled from two contaminated sites in Argentina and Germany was lower than in the same plant species sampled from non-contaminated sites [67]. On the other hand, 
colonization percentages of over $80 \%$ were recorded in plants growing in weathered crude oil in the Ecuador Amazon region [68]. Could the PH-induced stress have driven the plants into engaging more symbioses and promoted the growth of the AMF, which in turn could help alleviate the toxic effects? During the colonization of the roots, AMF develops multiple structures such as arbuscules and vesicles, which play an important part in the interaction with the host plant and the nutrition of the fungus [69]. Defoliation such as grazing by herbivores induces plant stress, in part due to loss of nutrients present in the foliage [70]. In a manual defoliation experiment, Medicago truncatula plants showed significantly lower vesicular colonization percentages than their non-defoliated counterparts [71]. Piippo et al. [72] found that grazing simulation through defoliation of two varieties of the biennial grassland herb Gentianella amarella decreased arbuscular colonization in the early flowering type, but on the other hand increased it in late flowering type plants [72]. Saito et al. [73] also observed a decrease of root colonization following the defoliation of grazing intolerant grass Myscanthus sinensis and at one sampling point for the grazing tolerant Zoysia japonica. Inversely, Ambrosino et al. [74] noted little to no effect of defoliation on total root AMF colonization. These contradictory results suggest that plant/host responses to stress can vary from one plant species to the other, and that different stress types would induce different responses, but also point to the host plant identity as a potential key for influencing AMF root communities. The bacterial inoculation in this experiment was associated with significantly increased root colonization percentages, but only in the contaminated substrate. AMF activity through its extra radical mycelium has been found to be influenced by soil microbiota assemblages [75]. The stress-inducing toxicity of PH contaminants could explain why significant changes in root colonization were only observed in the contaminated substrate, as it might have led to more dynamic and responsive root/AMF interactions.

\subsection{Inoculation Affects Plant Growth and PH Attenuation}

In this experiment, bacterial inoculation was associated with increased plant growth for some of the species; nevertheless, this did not translate to an increased PH attenuation rate. On the contrary, it significantly decreased the degradation rate, resulting in greater concentrations in the inoculated compared to the non-inoculated trays at the end of the experiment.

One would assume that the health of plants is likely to be a key component of the success or failure of the process. Nonetheless, our results suggest that improved plant growth does not necessarily lead to a successful remediation of PH contaminants. Wu et al. [76] used dual inoculation of ryegrass with a PAH-degrading bacteria and an AMF strain in order to attenuate PAHs levels, and they found that this approach was superior to single inoculation for the degradation of pyrene and phenanthrene. However, inoculation with the bacteria Acinetobacter sp. did not significantly increase ryegrass growth. Moreover, Bell et al. [77] showed that specialized soil bacterial assemblages obtained in culture are less efficient at degrading crude oil than a diverse microbiome.

\section{Conclusions}

In light of these results, it seems that a multifaceted approach should be favored in order to successfully shape the rhizosphere microbiome structure and function. It should take into account the physicochemical parameters of the soil environment, with a selection of plant/microbial assemblages that can persist in the given setting, while leading to predictable and reproducible effects on the plant host and soil.

Supplementary Materials: The following are available online at http://www.mdpi.com/2076-2607/8/4/602/s1, Table S1: Basic chemical characteristics of the substrates. Table S2: Bacterial isolates selected for the inoculation of plants, Table S3: AMF taxa from the 18S sequences after subsampling (150 sequences). LE: Lycopus europaeus; LS: Lythrum salicaria; PL: Persicaria lapathifolia; PC: Panicum capillare. Samples starting with A: Non-contaminated and non-inoculated; B: Contaminated and non-inoculated; C: Non-contaminated and inoculated; D: Contaminated and inoculated. The number after the first letter indicates the block from which the sample was taken. The number after the plant species designation indicates the plant species replicate in the treatment as there were 3 replicates of each plant species in each treatment (As shown in planting tray design in supplementary figure S1). Samples ending with a " $z$ " come from the 
rhizosphere and those without the " $z$ " represent root samples. Table S4: ANOVA analysis output from JMP for Shannon's index. Table S5: ANOVA analysis output from JMP for the Chao1 diversity index. Table S6: ANOVA analysis output from JMP for Pielou's equitability index. Table S7: Permanova analysis of the AMF communities based on the Bray-Curtis dissimilarity matrix. Table S8: ANOVA analysis output from JMP for the plant dry biomass production. Table S9: ANOVA analysis output from JMP for AMF root colonization percentages. Figure S1: Planting scheme in each tray (A), experimental setup (B), and a comparison between the non-contaminated soil and contaminated sediments mesocosms (C). Figure S2. Plant sampling example from a Persicaria lapathifolia. Figure S3. Bayesian phylogenetic tree based on nuclear small subunit (SSU) rDNA consensus sequences showing the distribution of the 23 OTUs recorded in this experiment (red labels) among the Glomeromycota tree.Sequence data were analyzed with the SSU sequences (black labels) from Krüger et al. (2012) and the closest matches recovered from MaarjAM database. The numbers on the nodes represent the Bayesian posterior probabilities. The scale represents the branch length corresponding to expected substitutions per site. Figure S4. Mycorrhizal structures observed in the plant roots under light microscopy.

Author Contributions: D.J.D. and I.E.d.1.P. designed and performed the experiment; I.E.d.1.P., F.E.P., M.S.-A., and M.H. supervised the project; D.J.D. analyzed the data; M.S.-A. and M.H. provided material and analytic tools; D.J.D., I.E.d.1.P., F.E.P., M.S.-A., and M.H. wrote the paper. All authors have read and agreed to the published version of the manuscript.

Funding: This work was funded by The Natural Sciences and Engineering Research Council of Canada (NSERC) Discovery Grant to MH (RGPIN-2018-04178), Genome Canada and Genome Quebec, which are gratefully acknowledged. D.J.D. received a scholarship from NSERC Mine of knowledge. We also thank ConocoPhillips for providing us with access to the Varennes field site.

Acknowledgments: We thank Geoffrey Hall for the in situ identification of the plants during seed collection, and Andrew Blakney for revising the manuscript. We also thank Alice Roy-Bolduc for help during seed collection, and David Denis for his assistance in the isolation and culturing of bacterial strains.

Conflicts of Interest: The authors declare no conflict of interest.

\section{References}

1. Van Der Heijden, M.G.A.; Bardgett, R.D.; Van Straalen, N.M. The unseen majority: Soil microbes as drivers of plant diversity and productivity in terrestrial ecosystems. Ecol. Lett. 2008, 11, 296-310. [CrossRef]

2. Berendsen, R.L.; Pieterse, C.M.; Bakker, P.A. The rhizosphere microbiome and plant health. Trends Plant Sci. 2012, 17, 478-486. [CrossRef] [PubMed]

3. Ping, L.; Boland, W. Signals from the underground: Bacterial volatiles promote growth in Arabidopsis. Trends Plant Sci. 2004, 9, 263-266. [CrossRef]

4. Dangl, J.L.; Horvath, D.M.; Staskawicz, B.J. Pivoting the Plant Immune System from Dissection to Deployment. Science 2013, 341, 746-751. [CrossRef] [PubMed]

5. Jambon, I.; Thijs, S.; Weyens, N.; Vangronsveld, J. Harnessing plant-bacteria-fungi interactions to improve plant growth and degradation of organic pollutants. J. Plant Interact. 2018, 13, 119-130. [CrossRef]

6. Ojuederie, O.B.; Babalola, O.O. Microbial and Plant-Assisted Bioremediation of Heavy Metal Polluted Environments: A Review. Int. J. Environ. Res. Public Health 2017, 14. [CrossRef] [PubMed]

7. Gkorezis, P.; Daghio, M.; Franzetti, A.; Van Hamme, J.D.; Sillen, W.; Vangronsveld, J. The Interaction between Plants and Bacteria in the Remediation of Petroleum Hydrocarbons: An Environmental Perspective. Front. Microbiol. 2016, 7, 1836. [CrossRef] [PubMed]

8. Alori, E.T.; Dare, M.O.; Babalola, O.O. Microbial Inoculants for Soil Quality and Plant Health. In Sustainable Agriculture Reviews; Lichtfouse, E., Ed.; Springer International Publishing: Cham, Switzerland, 2017; pp. 281-307. [CrossRef]

9. Fox, J.L. Agricultural probiotics enter spotlight. Nat. Publ. 2015, 33, 122. [CrossRef] [PubMed]

10. Kaminsky, L.M.; Trexler, R.V.; Malik, R.J.; Hockett, K.L.; Bell, T.H. The Inherent Conflicts in Developing Soil Microbial Inoculants. Trends Biotechnol. 2019, 37, 140-151. [CrossRef]

11. Ratzke, C.; Gore, J. Modifying and reacting to the environmental $\mathrm{pH}$ can drive bacterial interactions. PLoS Biol. 2018, 16, e2004248. [CrossRef]

12. Kallala, N.; M'sehli, W.; Jelali, K.; Kais, Z.; Mhadhbi, H. Inoculation with Efficient Nitrogen Fixing and Indoleacetic Acid Producing Bacterial Microsymbiont Enhance Tolerance of the Model Legume Medicago truncatula to Iron Deficiency. BioMed Res. Int. 2018, 2018, 14. [CrossRef] 
13. Yergeau, E.; Bell, T.; Champagne, J.; Maynard, C.; Tardif, S.; Tremblay, J.; Greer, C. Transplanting soil microbiomes leads to lasting effects on willow growth, but not on the rhizosphere microbiome. Front. Microbiol. 2015, 6. [CrossRef]

14. Dagher, D.J.; de la Providencia, I.E.; Pitre, F.E.; St-Arnaud, M.; Hijri, M. Plant Identity Shaped Rhizospheric Microbial Communities More Strongly Than Bacterial Bioaugmentation in Petroleum Hydrocarbon-Polluted Sediments. Front. Microbiol. 2019, 10. [CrossRef]

15. Smith, S.E.; Read, D.J. Mycorrhizal Symbiosis; Elsevier: Amsterdam, The Netherlands, 2010; Available online: ScienceDirect.com (accessed on 17 January 2020).

16. Abdel Latef, A.A.H.; Chaoxing, H. Effect of arbuscular mycorrhizal fungi on growth, mineral nutrition, antioxidant enzymes activity and fruit yield of tomato grown under salinity stress. Sci. Hortic. 2011, 127, 228-233. [CrossRef]

17. Jakobsen, I.; Smith, S.E.; Smith, F.A. Function and Diversity of Arbuscular Mycorrhizae in Carbon and Mineral Nutrition. In Mycorrhizal Ecology; van der Heijden, M.G.A., Sanders, I.R., Eds.; Springer Berlin Heidelberg: Berlin/Heidelberg, Germany, 2003.

18. Posta, K.; Duc, N.H. Benefits of Arbuscular Mycorrhizal Fungi Application to Crop Production under Water Scarcity. In Drought (Aridity); IntechOpen: London, UK, 2019.

19. Wu, Z.; McGrouther, K.; Huang, J.; Wu, P.; Wu, W.; Wang, H. Decomposition and the contribution of glomalin-related soil protein (GRSP) in heavy metal sequestration: Field experiment. Soil Biol. Biochem. 2014, 68, 283-290. [CrossRef]

20. Hajiboland, R.; Aliasgharzadeh, N.; Laiegh, S.F.; Poschenrieder, C. Colonization with arbuscular mycorrhizal fungi improves salinity tolerance of tomato (Solanum lycopersicum L.) plants. Plant and Soil 2010, 331, 313-327. [CrossRef]

21. Begum, N.; Qin, C.; Ahanger, M.A.; Raza, S.; Khan, M.I.; Ashraf, M.; Ahmed, N.; Zhang, L. Role of Arbuscular Mycorrhizal Fungi in Plant Growth Regulation: Implications in Abiotic Stress Tolerance. Front. Plant Sci. 2019, 10. [CrossRef]

22. Song, Y.; Chen, D.; Lu, K.; Sun, Z.; Zeng, R. Enhanced tomato disease resistance primed by arbuscular mycorrhizal fungus. Front. Plant Sci. 2015, 6. [CrossRef]

23. Bruisson, S.; Maillot, P.; Schellenbaum, P.; Walter, B.; Gindro, K.; Deglène-Benbrahim, L. Arbuscular mycorrhizal symbiosis stimulates key genes of the phenylpropanoid biosynthesis and stilbenoid production in grapevine leaves in response to downy mildew and grey mould infection. Phytochemistry 2016, 131, 92-99. [CrossRef]

24. St-Arnaud, M.; Vujanovic, V. Effect of the arbuscular mycorrhizal symbiosis on plant diseases and pests. In Mycorrhizae in Crop Production; Haworth: New York, NY, USA, 2007; pp. 67-122.

25. Rillig, M.C.; Mummey, D.L. Mycorrhizas and soil structure. New Phytol. 2006, 171, 41-53. [CrossRef]

26. Rillig, M.C.; Wright, S.F.; Eviner, V.T. The role of arbuscular mycorrhizal fungi and glomalin in soil aggregation: Comparing effects of five plant species. Plant and Soil 2002, 238, 325-333. [CrossRef]

27. Bedini, S.; Pellegrino, E.; Avio, L.; Pellegrini, S.; Bazzoffi, P.; Argese, E.; Giovannetti, M. Changes in soil aggregation and glomalin-related soil protein content as affected by the arbuscular mycorrhizal fungal species Glomus mosseae and Glomus intraradices. Soil Biol. Biochem. 2009, 41, 1491-1496. [CrossRef]

28. Joner, E.J.; Johansen, A.; Loibner, A.P.; dela Cruz, M.A.; Szolar, O.H.J.; Portal, J.-M.; Leyval, C. Rhizosphere Effects on Microbial Community Structure and Dissipation and Toxicity of Polycyclic Aromatic Hydrocarbons (PAHs) in Spiked Soil. Environ. Sci. Technol. 2001, 35, 2773-2777. [CrossRef]

29. Joner, E.; Leyval, C. Phytoremediation of organic pollutants using mycorrhizal plants: A new aspect of rhizosphere interactions. In Sustainable Agriculture; Springer: Dordrecht, The Netherlands, 2003; Volume 23, pp. 495-502.

30. Barea, J.; Gryndler, M.; Lemanceau, P.; Schüepp, H.; Azcón, R. The rhizosphere of mycorrhizal plants. In Mycorrhizal Technology in Agriculture; Springer: New York, NY, USA, 2002; pp. 1-18.

31. Jeffries, P.; Gianinazzi, S.; Perotto, S.; Turnau, K.; Barea, J.-M. The contribution of arbuscular mycorrhizal fungi in sustainable maintenance of plant health and soil fertility. Biol. Fertility Soils 2003, 37, 1-16. [CrossRef]

32. Li, Q.; Ling, W.; Gao, Y.; Li, F.; Xiong, W. Arbuscular mycorrhizal bioremediation and its mechanisms of organic pollutants-contaminated soils. Ying yong sheng tai xue bao = J. Appl. Ecol. 2006, 17, 2217-2221.

33. Lecomte, J.; St-Arnaud, M.; Hijri, M. Isolation and identification of soil bacteria growing at the expense of arbuscular mycorrhizal fungi. FEMS Microbiol. Lett. 2011, 317, 43-51. [CrossRef] [PubMed] 
34. Scheublin, T.R.; Sanders, I.R.; Keel, C.; van der Meer, J.R. Characterisation of microbial communities colonising the hyphal surfaces of arbuscular mycorrhizal fungi. ISME J. 2010, 4, 752-763. [CrossRef]

35. Taktek, S.; St-Arnaud, M.; Piché, Y.; Fortin, J.A.; Antoun, H. Igneous phosphate rock solubilization by biofilm-forming mycorrhizobacteria and hyphobacteria associated with Rhizoglomus irregulare DAOM 197198. Mycorrhiza 2017, 27, 13-22. [CrossRef]

36. Emam, T. Local soil, but not commercial AMF inoculum, increases native and non-native grass growth at a mine restoration site. Restor. Ecol. 2016, 24, 35-44. [CrossRef]

37. Desjardins, D.; Nissim, W.G.; Pitre, F.E.; Naud, A.; Labrecque, M. Distribution patterns of spontaneous vegetation and pollution at a former decantation basin in southern Québec, Canada. Ecol. Eng. 2014, 64, 385-390. [CrossRef]

38. Bell, T.H.; Hassan, S.E.-D.; Lauron-Moreau, A.; Al-Otaibi, F.; Hijri, M.; Yergeau, E.; St-Arnaud, M. Linkage between bacterial and fungal rhizosphere communities in hydrocarbon-contaminated soils is related to plant phylogeny. ISME J. 2014, 8, 331-343. [CrossRef]

39. Stefani, F.O.; Bell, T.H.; Marchand, C.; de la Providencia, I.E.; El Yassimi, A.; St-Arnaud, M.; Hijri, M. Culture-dependent and-independent methods capture different microbial community fractions in hydrocarbon-contaminated soils. PLoS ONE 2015, 10, e0128272. [CrossRef]

40. Lee, J.; Lee, S.; Young, J.P. Improved PCR primers for the detection and identification of arbuscular mycorrhizal fungi. FEMS Microbiol. Ecol. 2008, 65, 339-349. [CrossRef] [PubMed]

41. Renaut, S.; Daoud, R.; Masse, J.; Vialle, A.; Hijri, M. Inoculation with Rhizophagus Irregularis Does Not Alter Arbuscular Mycorrhizal Fungal Community Structure within the Roots of Corn, Wheat, and Soybean Crops. Microorganisms 2020, 8. [CrossRef] [PubMed]

42. Dalpé, Y.; Séguin, S.M. Microwave-assisted technology for the clearing and staining of arbuscular mycorrhizal fungi in roots. Mycorrhiza 2013, 23, 333-340. [CrossRef] [PubMed]

43. McGonigle, T.P.; Miller, M.H.; Evans, D.G.; Fairchild, G.L.; Swan, J.A. A new method which gives an objective measure of colonization of roots by vesicular-arbuscular mycorrhizal fungi. New Phytol. 1990, 115, 495-501. [CrossRef]

44. Pylro, V.S.; Roesch, L.F.W.; Morais, D.K.; Clark, I.M.; Hirsch, P.R.; Tótola, M.R. Data analysis for $16 \mathrm{~S}$ microbial profiling from different benchtop sequencing platforms. J. Microbiol. Methods 2014, 107, 30-37. [CrossRef]

45. Pylro, V.S.; Roesch, L.F.W.; Ortega, J.M.; Amaral, A.M.; Tótola, M.R.; Hirsch, P.R.; Rosado, A.S.; Góes-Neto, A.; da Costa da Silva, A.L.; Rosa, C.A.; et al. Brazilian Microbiome Project: Revealing the Unexplored Microbial Diversity-Challenges and Prospects. Microb. Ecol. 2013, 67, 237-241. [CrossRef]

46. Kruger, M.; Kruger, C.; Walker, C.; Stockinger, H.; Schussler, A. Phylogenetic reference data for systematics and phylotaxonomy of arbuscular mycorrhizal fungi from phylum to species level. New Phytol. 2012, 193, 970-984. [CrossRef]

47. Öpik, M.; Vanatoa, A.; Vanatoa, E.; Moora, M.; Davison, J.; Kalwij, J.M.; Reier, Ü.; Zobel, M. The online database MaarjAM reveals global and ecosystemic distribution patterns in arbuscular mycorrhizal fungi (Glomeromycota). New Phytol. 2010, 188, 223-241. [CrossRef]

48. Edgar, R.C. MUSCLE: Multiple sequence alignment with high accuracy and high throughput. Nucleic Acids Res. 2004, 32, 1792-1797. [CrossRef]

49. Kearse, M.; Moir, R.; Wilson, A.; Stones-Havas, S.; Cheung, M.; Sturrock, S.; Buxton, S.; Cooper, A.; Markowitz, S.; Duran, C.; et al. Geneious Basic: An integrated and extendable desktop software platform for the organization and analysis of sequence data. Bioinformatics (Oxf., Engl. ) 2012, 28, 1647-1649. [CrossRef]

50. Darriba, D.; Taboada, G.L.; Doallo, R.; Posada, D. jModelTest 2: More models, new heuristics and parallel computing. Nat. Methods 2012, 9, 772. [CrossRef]

51. Guindon, S.; Gascuel, O. A simple, fast, and accurate algorithm to estimate large phylogenies by maximum likelihood. Syst. Biol. 2003, 52, 696-704. [CrossRef] [PubMed]

52. Ronquist, F.; Huelsenbeck, J.P. MRBAYES: Bayesian inference of phylogenetic trees. Bioinformatics (Oxf., Engl.) 2001, 17, 754-755. [CrossRef]

53. Pielou, E.C. The measurement of diversity in different types of biological collections. J. Theor. Biol. 1966, 13, 131-144. [CrossRef]

54. Xu, X.; Chen, C.; Zhang, Z.; Sun, Z.; Chen, Y.; Jiang, J.; Shen, Z. The influence of environmental factors on communities of arbuscular mycorrhizal fungi associated with Chenopodium ambrosioides revealed by MiSeq sequencing investigation. Sci. Rep. 2017, 7, 45134. [CrossRef] 
55. Krüger, C.; Kohout, P.; Janoušková, M.; Püschel, D.; Frouz, J.; Rydlová, J. Plant Communities Rather than Soil Properties Structure Arbuscular Mycorrhizal Fungal Communities along Primary Succession on a Mine Spoil. Front. Microbiol. 2017, 8. [CrossRef]

56. Zhang, J.; Wang, F.; Che, R.; Wang, P.; Liu, H.; Ji, B.; Cui, X. Precipitation shapes communities of arbuscular mycorrhizal fungi in Tibetan alpine steppe. Sci. Rep. 2016, 6, 23488. [CrossRef]

57. Dumbrell, A.J.; Nelson, M.; Helgason, T.; Dytham, C.; Fitter, A.H. Relative roles of niche and neutral processes in structuring a soil microbial community. ISME J. 2009, 4, 337. [CrossRef]

58. Tropini, C.; Moss, E.L.; Merrill, B.D.; Ng, K.M.; Higginbottom, S.K.; Casavant, E.P.; Gonzalez, C.G.; Fremin, B.; Bouley, D.M.; Elias, J.E.; et al. Transient Osmotic Perturbation Causes Long-Term Alteration to the Gut Microbiota. Cell 2018, 173, 1742-1754. [CrossRef]

59. Iffis, B.; St-Arnaud, M.; Hijri, M. Petroleum Contamination and Plant Identity Influence Soil and Root Microbial Communities While AMF Spores Retrieved from the Same Plants Possess Markedly Different Communities. Front. Plant Sci. 2017, 8, 1381. [CrossRef]

60. Iffis, B.; St-Arnaud, M.; Hijri, M. Petroleum hydrocarbon contamination, plant identity and arbuscular mycorrhizal fungal (AMF) community determine assemblages of the AMF spore-associated microbes. Environ. Microbiol. 2016, 18, 2689-2704. [CrossRef]

61. Taktek, S.; Trépanier, M.; Servin, P.M.; St-Arnaud, M.; Piché, Y.; Fortin, J.A.; Antoun, H. Trapping of phosphate solubilizing bacteria on hyphae of the arbuscular mycorrhizal fungus Rhizophagus irregularis DAOM 197198. Soil Biol. Biochem. 2015, 90, 1-9. [CrossRef]

62. Miransari, M. Interactions between arbuscular mycorrhizal fungi and soil bacteria. Appl. Microbiol. Biotechnol. 2011, 89, 917-930. [CrossRef]

63. De la Providencia, I.E.; Stefani, F.O.P.; Labridy, M.; St-Arnaud, M.; Hijri, M. Arbuscular mycorrhizal fungal diversity associated with Eleocharis obtusa and Panicum capillare growing in an extreme petroleum hydrocarbon-polluted sedimentation basin. FEMS Microbiol. Lett. 2015, 362. [CrossRef]

64. Hassan, S.E.-D.; Bell, T.H.; Stefani, F.O.P.; Denis, D.; Hijri, M.; St-Arnaud, M. Contrasting the Community Structure of Arbuscular Mycorrhizal Fungi from Hydrocarbon-Contaminated and Uncontaminated Soils following Willow (Salix spp. L.) Planting. PLoS ONE 2014, 9, e102838. [CrossRef]

65. Hart, M.M.; Reader, R.J. The role of the external mycelium in early colonization for three arbuscular mycorrhizal fungal species with different colonization strategies. Pedobiologia 2005, 49, 269-279. [CrossRef]

66. Hart, M.M.; Reader, R.J. Taxonomic basis for variation in the colonization strategy of arbuscular mycorrhizal fungi. New Phytol. 2002, 153, 335-344. [CrossRef]

67. Cabello, M.N. Hydrocarbon pollution: Its effect on native arbuscular mycorrhizal fungi (AMF). FEMS Microbiol. Ecol. 1997, 22, 233-236. [CrossRef]

68. Garcés-Ruiz, M.; Senés-Guerrero, C.; Declerck, S.; Cranenbrouck, S. Arbuscular Mycorrhizal Fungal Community Composition in Carludovica palmata, Costus scaber and Euterpe precatoria from Weathered Oil Ponds in the Ecuadorian Amazon. Front. Microbiol. 2017, 8. [CrossRef] [PubMed]

69. Varela-Cervero, S.; López-García, Á.; Barea, J.M.; Azcón-Aguilar, C. Differences in the composition of arbuscular mycorrhizal fungal communities promoted by different propagule forms from a Mediterranean shrubland. Mycorrhiza 2016, 26, 489-496. [CrossRef] [PubMed]

70. Tuomi, J.; Niemelä, P.; Haukioja, E.; Sirén, S.; Neuvonen, S. Nutrient stress: An explanation for plant anti-herbivore responses to defoliation. Oecologia 1984, 61, 208-210. [CrossRef] [PubMed]

71. IJdo, M.; Schtickzelle, N.; Cranenbrouck, S.; Declerck, S. Do arbuscular mycorrhizal fungi with contrasting life-history strategies differ in their responses to repeated defoliation? FEMS Microbiol. Ecol. 2010, 72, 114-122. [CrossRef]

72. Piippo, S.; Markkola, A.; Härmä, E.; Tuomi, J. Do compensatory shoot growth and mycorrhizal symbionts act as competing above- and below-ground sinks after simulated grazing? Plant Ecol. 2011, 212, $33-42$. [CrossRef]

73. Saito, K.; Suyama, Y.; Sato, S.; Sugawara, K. Defoliation effects on the community structure of arbuscular mycorrhizal fungi based on $18 \mathrm{~S}$ rDNA sequences. Mycorrhiza 2004, 14, 363-373. [CrossRef]

74. Ambrosino, M.L.; Busso, C.A.; Cabello, M.N.; Velázquez, M.S.; Torres, Y.A.; Ithurrart, L.S.; Cardillo, D.S.; Palomo, I.R. Total and structure colonization by arbuscular mycorrhizal fungi in native, perennial grasses of different forage quality exposed to defoliation. J. King Saud Univ. Sci. 2018, 32, 377-383. [CrossRef] 
75. Svenningsen, N.B.; Watts-Williams, S.J.; Joner, E.J.; Battini, F.; Efthymiou, A.; Cruz-Paredes, C.; Nybroe, O.; Jakobsen, I. Suppression of the activity of arbuscular mycorrhizal fungi by the soil microbiota. ISME J. 2018, 12, 1296-1307. [CrossRef] [PubMed]

76. Wu, F.; Yu, X.; Wu, S.; Wong, M. Effects of Inoculation of PAH-degrading Bacteria and Arbuscular Mycorrhizal Fungi on Responses of Ryegrass to Phenanthrene and Pyrene. Int. J. Phytoremediation 2014, 16, 109-122. [CrossRef] [PubMed]

77. Bell, T.H.; Stefani, F.O.P.; Abram, K.; Champagne, J.; Yergeau, E.; Hijri, M.; St-Arnaud, M. A Diverse Soil Microbiome Degrades More Crude Oil than Specialized Bacterial Assemblages Obtained in Culture. Appl. Environ. Microbiol. 2016, 82, 5530-5541. [CrossRef]

(C) 2020 by the authors. Licensee MDPI, Basel, Switzerland. This article is an open access article distributed under the terms and conditions of the Creative Commons Attribution (CC BY) license (http://creativecommons.org/licenses/by/4.0/). 